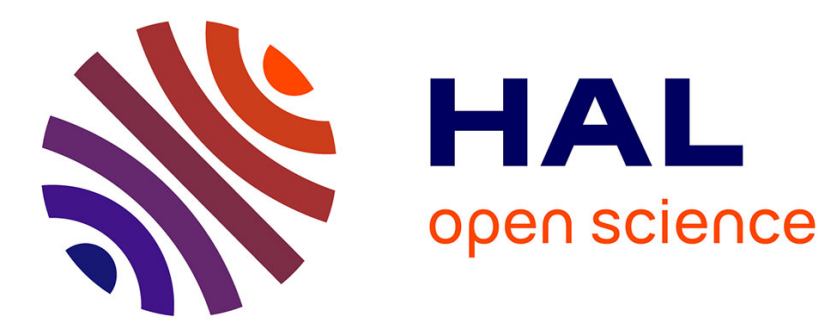

\title{
Shielding with superconductors in small magnetic fields
}

A.F. Hildebrandt

\section{To cite this version:}

A.F. Hildebrandt. Shielding with superconductors in small magnetic fields. Revue de Physique Appliquée, 1970, 5 (1), pp.49-52. 10.1051/rphysap:019700050104900 . jpa-00243374

\section{HAL Id: jpa-00243374 https://hal.science/jpa-00243374}

Submitted on 1 Jan 1970

HAL is a multi-disciplinary open access archive for the deposit and dissemination of scientific research documents, whether they are published or not. The documents may come from teaching and research institutions in France or abroad, or from public or private research centers.
L'archive ouverte pluridisciplinaire HAL, est destinée au dépôt et à la diffusion de documents scientifiques de niveau recherche, publiés ou non, émanant des établissements d'enseignement et de recherche français ou étrangers, des laboratoires publics ou privés. 


\title{
SHIELDING WITH SUPERGONDUGTORS IN SMALL MAGNETIG FIELDS ${ }^{(1)}$
}

\author{
By A. F. HILDEBRANDT, \\ University of Houston, Department of Physics, Houston, Texas (U.S.A.).
}

\begin{abstract}
The shielding properties of a superconducting lead shell have been investigated in fields of the order of $10^{-4}$ gauss. The small ambient fields were obtained with a room size $\mu$-metal shield. Fields of less than 2 microgauss were obtained over a sphere of $7.5 \mathrm{~cm}$ diameter. This region is at room temperature and is suitable for magnetometer testing.
\end{abstract}

The testing and calibration of magnetometers for space applications requires the development of field free regions. The Meissner effect in a superconducting shield in the form of a lead shell in a small ambient field $\left(<10^{-4}\right.$ gauss $)$ has resulted in a final static magnetic field of less than $2 \times 10^{-6}$ gauss over a region of $7.5 \mathrm{~cm}$ diameter and $15 \mathrm{~cm}$ length. The Meissner effect arises in a superconductor such as lead due to a smaller free energy of the superconductor when the flux is expelled from the bulk material rather than being frozen in as would be the case for perfect conductivity alone [1] as shown in figure 1 . The small initial fields of less than 100 microgauss were obtained with a room size double wall $\mu$-metal shield as shown in figure 2 [2]. A brief account of this work

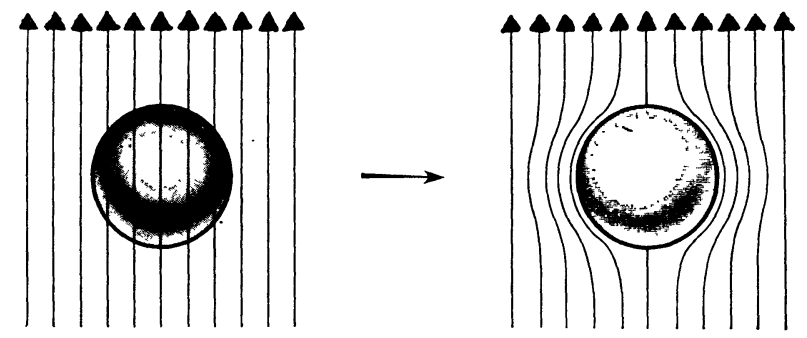

FIG. 1. - Meissner effect in a superconducting sphere cooled in constant applied field. The lines of induction $B$ are expelled from the sphere on passing below the transition temperature.

has been given elsewhere [3]. A shield similar to that shown has recently been constructed in our laboratory [4]. The shield can be disassembled and moved if necessary. The wood battens supply mechanical pressure on the three inch wide $\mu$-metal strips in order to make a magnetic contact between two adjacent panels. The inside room dimensions are those of a six foot cube. A partial vacuum of .2 PSI between the inner and outer door provides a stable magnetic contact.

The ambient field of such a room immediately after assembly can be as large as 5,000 microgauss. This large ambient field can systematically be reduced either

(1) Supported by National Aeronautics and Space Administration under NASW-6 and NASA Grant 44005-022.

RevUe De Physique appliquéE. - T. 5. No 1. FÉVRIER 1970.

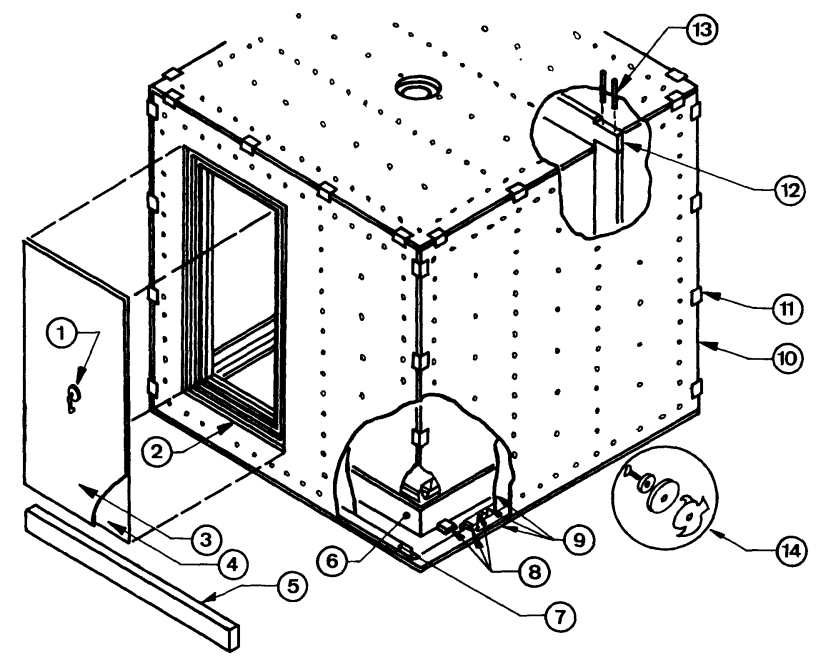

FIG. 2. - $\mu$-metal shielded room.

(1), Alum-handle; (2), $1^{\prime \prime}$ plywood with $.060^{\prime \prime} \mu$-metal and gasket supports; (3), $1^{\prime \prime}$ plywood; (4), .060" $\mu$-metal; (5), outside door support (wooden) with alum-guide for casters; (6), wooden platform for inside box; (7), $\mu$-metal with $1 / 2^{\prime \prime} R$; (8), wooden battens with $\mu$-metal strips; (9), $1^{\prime \prime}$ plywood, .060" $\mu$-metal; (10), $1^{\prime \prime}$ plywood sides; (11), aluminium brackets; (12), outer box rests on wooden battens; (13), wooden dowling; (14), brass "'T" nut.

by moving tape degaussers over the walls or with a large A.C. demagnetizing coil. It has been found that a 25 ampere 60 cycle per second current in a $70 \mathrm{~cm}$ diameter 300 turn coil is sufficient to demagnetize the inside of the shield. The advantage of a two wall shield over a three wall shield is that the demagnetization is always possible with inside and outside coils. The variation of the ambient field with temperature at an ambient field of 100 microgauss is about 10 microgauss per ${ }^{\circ} \mathrm{C}$ per axis. This temperature coefficient requires that the surroundings be temperature controlled and the walls thermally insulated.

A typical gradient of such a room at the center is .5 microgauss per $\mathrm{cm}$ over a $7.5 \mathrm{~cm}$ diameter sphere. The small gradient is the most important feature of a large shielded room. A reduced field at a point is always possible, but the attainment of a reduced field over a large region in small shields requires conside- 
rable time and is very susceptible to change by external fields.

The ambient field of the room is usually not reduced below 100 microgauss by continued demagnetization because of temperature variations, but it is found more convenient to cancel the ambient field with an applied field of Helmholtz coils. A triad of $100 \mathrm{~cm}$ diameter Helmholtz coils with geometric center at the center of the shield room has been found adequate in this connection. Although gradients have not been serious, a first order gradient correction is available where current can be supplied to the individual coils separately. The fields are measured with a single axis fluxgate probe at room temperature. The sensitivity of the fluxgate used was \pm 2 microgauss. Calibration was obtained with a known current in a long uniformly wound solenoid. The zero of the probe was found by rotating through $180^{\circ}$.

The superconducting shield was concentric with a series of Dewars shown in figure 3 with the bottom of

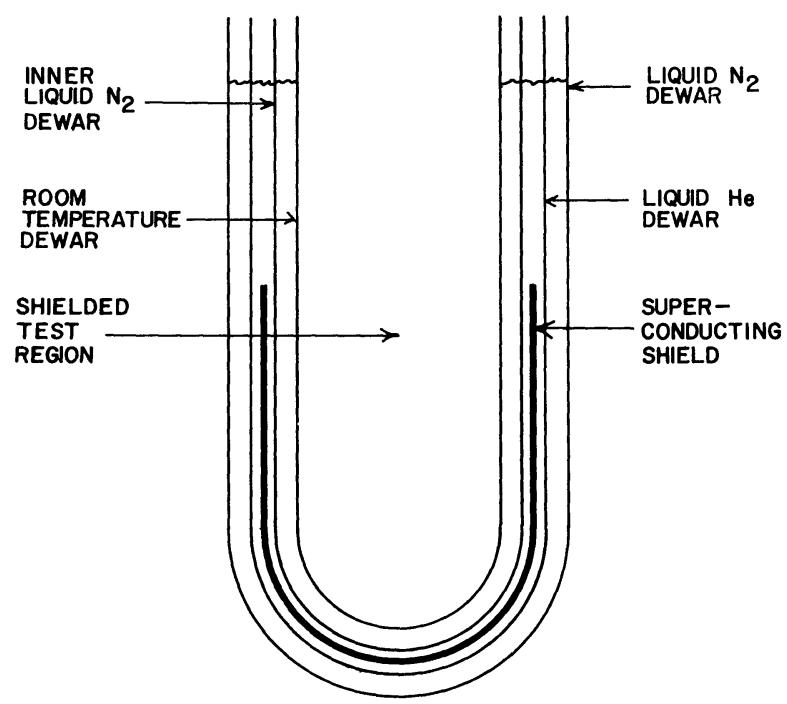

FIG. 3. - Superconducting lead shield for magnetometer calibration. Diameter of the inner dewar is $7.5 \mathrm{~cm}$.

the shield at the center of the Helmholtz coils. The superconducting shield was fabricated from freshly cut sheets of $99.9999 \%$ pure lead by fusing without flux. The dimensions of the lead shield were that of a thin wall tube of $37 \mathrm{~cm}$ length with an hemispherical bottom. The diameter of the tube was $15 \mathrm{~cm}$ and the wall thickness was $.025 \mathrm{~cm}$. The inner diameter of the room temperature Dewar was $7.5 \mathrm{~cm}$. The field in the shell could be mapped over a larger diameter with a $2.5 \mathrm{~cm}$ diameter Dewar containing the probe placed directly inside the lead shell in the helium bath. The liquid helium was either transfered directly through the centrally located hole in the room shown in figure 2 or from a glass storage Dewar inside the room. Precautions were taken to assure that the transfer tube was non-magnetic. Also, to assure a good uniform Meissner effect the transition temperature was traversed slowly with the transfer tube on the bottom of the shield. Because the transition temperature of lead is $7.2 \mathrm{oK}$ and the boiling point of helium is $4.2 \mathrm{oK}$, the cooling was accomplished by the gas phase. The importance of cooling from the inside is not fully understood, but it should be noted that in a small ambient field there will, in general, result two currents on the superconducting shell. One inside the tube, which is quantized, and the other, the shielding current on the outside, which is not quantized. If the inside current is zero then no flux need penetrate the superconductor and one can obtain a zero field region. If on the other hand a non-zero fluxoid is established, such as when cooling the top of the shield first, then the flux must ultimately penetrate the bulk material.

The results of six experiments are shown in figure 4 where the trapped axial field $B_{t}$ is plotted versus the

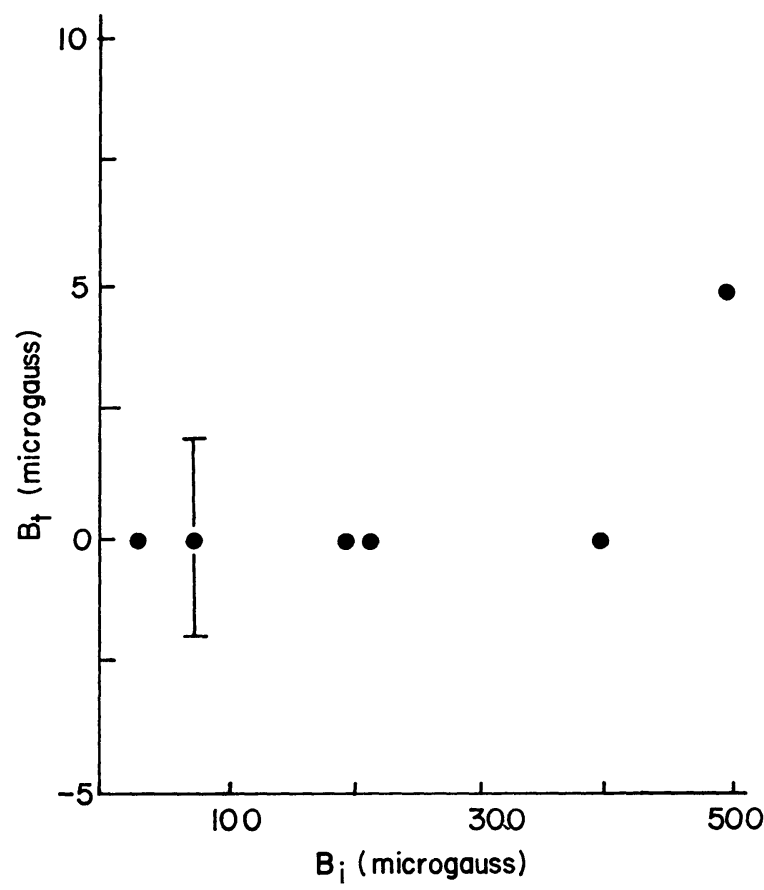

FIG. 4. - Trapped axial magnetic field $B_{t}$ for applied initial field $B_{i}$. The accuracy of measurement was \pm 2 microgauss.

initial axial field $B_{i}$. A reduction in field by a factor of 100 is seen possible. Using the accuracy of measurement of 2 microgauss as an upper bound of the field for the points near the origin, the area of the tube and the flux quantum of $\varphi_{0}=2.07 \times 10^{-7}$ gauss. $\mathrm{cm}^{2}[5]$, it is calculated that less than two thousand quanta are trapped. The results show that it may ultimately be possible to obtain field free regions that do not contain a single flux quantum as proposed by Fairbanks [6]. It is suggested that if an aluminum shell were placed inside a lead shell and cooled slowly through the aluminum transition temperature by pumping on the helium, a further reduction should be possible. The occurrence of any thermal currents in the aluminum should be reduced by the excellent thermal conductivity of liquid helium at the transition temperature of $1.18^{\circ} \mathrm{K}$, and because image currents in the superconducting lead would create an unfavorable free energy condition in the aluminum. For present purposes it can be concluded that the Meissner effect is effective at reduced fields.

An axial map of the shield for the initial field of 150 microgauss is shown in figure 5. The field was less than 2 microgauss for a length of $15 \mathrm{~cm}$. The field perpendicular to the axis was also less than 2 microgauss. Extensive data for each run could not be 


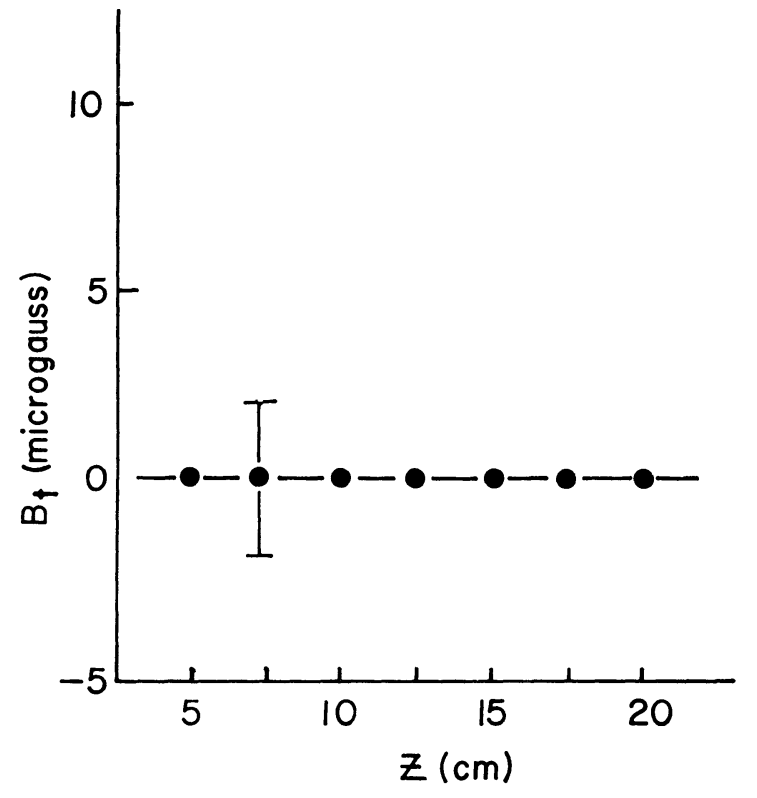

Frg. 5. - Axial field measurements vs. Distance from bottom of shield for $B_{i}$ equal to 150 microgauss.

obtained, because the original Dewar design limited each experiment to about $30 \mathrm{mn}$.

The A.C. shielding characteristics of a perfect conducting cylindrical tube for frequencies less than cut off are reported elsewhere [7]. As an example all $\mathrm{TE}$ and TM modes are attenuated, at least $30 \mathrm{db}$ for each length equal to diameter. Since the super-

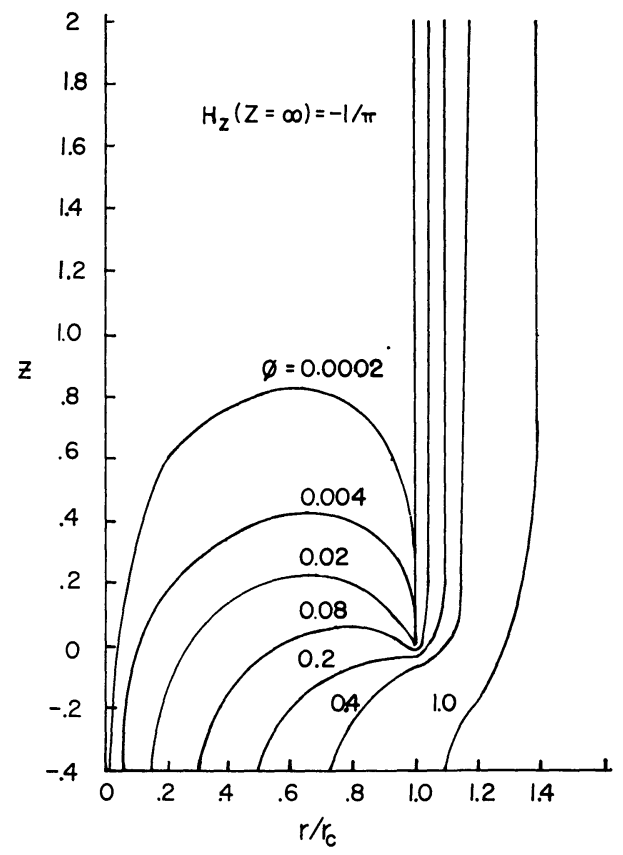

FIG. 6. - Plot of lines of constant flux for open end of shield. The applied field is assumed uniform and the trapped flux is zero. conductor is a perfect conductor down to zero frequency, unlike that for copper, a superconducting tube will attenuate all frequencies below cut off.

In order to evaluate the shielding behavior of the open end of the superconducting shield in a steady axial magnetic field, we have made an extension of a previous calculation of field configurations of superconducting shells [8]. The boundary condition here is that the total flux enclosed by the tube is zero and the normal component of $B$ is zero on the superconducting surface. In the absence of the shield, the flux is normalized to unity for a radius $r_{s}=1$ (the radius of the superconducting shell) and a uniform applied field of $1 / \pi$. Since the fluxoid or net trapped flux is assumed zero, the field configuration is such that the field enters the shell near the axis and emerges at the rim. In figure 6 the lines of constant flux are along the field direction. Figure 7 is a plot

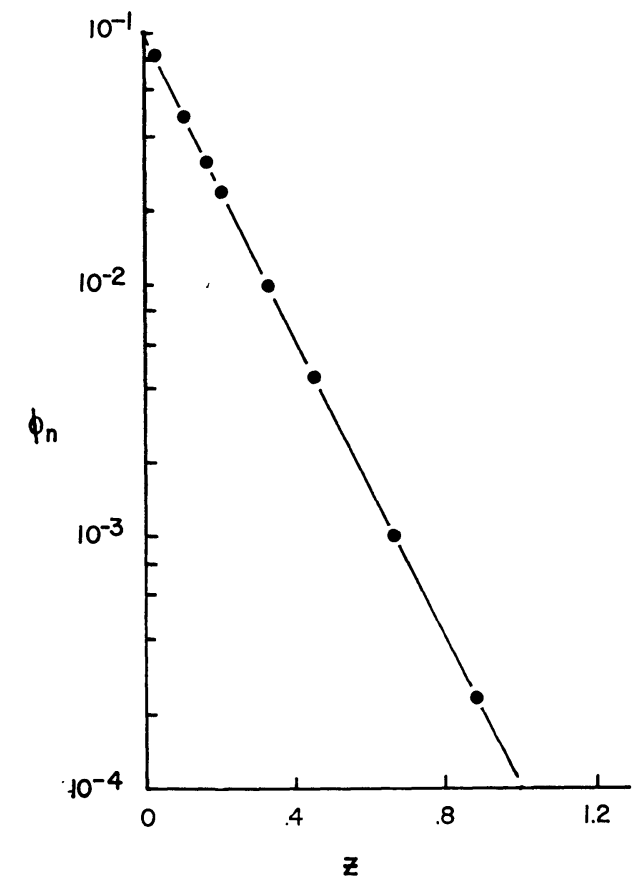

FrG. 7. - Shielding of flux by superconducting tube vs. axial distance for $r=2 / 3 r_{s}$.

of the amount of flux in a circle of radius $r=2 / 3 r_{s}$ entering the end of the tube versus axial distance. $Z=1$ corresponds to an axial distance equal to the diameter of the shell.

These results show that a superconducting shield in conjunction with a conventional shield can provide a noise free test region having a very small ambient field. When using such a region for calibration of a magnetometer with a solenoid, it should be noted that the total flux is conserved along the axis. This requires a small but accurately known correction. Calibrations perpendicular to the axis are complicated by the presence of images in the superconducting walls.

\section{REFERENCES}

[1] Meissner (W.) and OChSENFELD (R.), Naterwiss 21, 787 ; Low Temperature Solid State Physics, R. Rosenberg, p. 152, Oxford Press.

[2] The $\mu$-metal is Allegheny Ludlum 4-79 Permalloy.
[3] Hildebrandt (A. F.) and Ellieman (D. D.), 0-1 Proceedings of the "Symposium on the Physics of Superconducting Devices", April 28-29, 1967, University of Virginia, Charlottesville. 
[4] Supported by a grant from the Research Corporation.

[5] Deaver Jr (B. S.) and Fairbanks (W. M.), Phys. Rev. Letters, 1961, 1, 43 ; Dol, (R.) and NAUBaUer (M.), Phys. Rev. Letters, 1961, 1, 51.

[6] FaIRbanks (W. M.), A-1 Proceedings of the "Symposium on the Physics of Superconducting Devices", April 28-29, 1967, University of Virginia, Charlottesville.
[7] Fields and Waves in Modern Radio, Simon Ramo and John Whinnery, p. 323, John Wiley and Sons.

[8] Hildebrandt (A. F.), Wahlquist (H.) and ElileMAN (D. D.), Configurations of Superconducting Shells Required for Near Critical Uniform Magnetic Fields, J. Appl. Physics, 1962, 33, 1798. 